УДК 541.183.123.8

\title{
БИОКАТАЛИТИЧЕСКИЕ СВОЙСТВА ИММОБИЛИЗОВАННОЙ ИНУЛИНАЗЫ
}

\author{
() И.В. Шкутина", О.Ф. Стоянова, В.Ф. Селеменев \\ Воронежский государственный университет, Университетская пл., 1, \\ Воронеж, 394006 (Россия), e-mail: irn55@mail.ru
}

\begin{abstract}
Предложен гетерогенный биокатализатор на основе инулиназы, иммобилизованной на неионогенном сорбенте Стиросорб. Проведено исследование термической и кислотной инактивации свободной и иммобилизованной инулиназы. Рассчитаны соответствующие значения констант инактивации. Выявлено увеличение термостабильности иммобилизованного фермента по сравнению со свободным. Установлена возможность использования иммобилизованного фермента в реакции гидролиза инулина в течение 10 циклов.

Ключевые слова: инулиназа, Стиросорб, иммобилизация, каталитическая активность, кислотная, термическая инактивация, константа инактивации.
\end{abstract}

\section{Введение}

В технологии переработки растительного сырья и получения пищевых продуктов значительная роль принадлежит карбогидразам. В частности, инулиназа (2,1- $\beta$-D-фруктан-фруктаногидролаза, КФ 3.2.1.7) гидролизует инулин до фруктозы и фруктоолигосахаридов. Условия проведения ферментативной реакции более мягкие, чем кислотного гидролиза инулина, требующего высокой температуры, низких значений рН среды и использования специального кислотоустойчивого оборудования. Применение в промышленном масштабе гетерогенных биокаталитических процессов является более экономичным, чем гомогенных, поскольку появляется возможность использования биокатализаторов в течение нескольких циклов в сочетании с высокой селективностью и невысокой стоимостью их приготовления. В ряде случаев иммобилизация может повысить стабильность фермента при хранении и действии денатурирующих факторов среды, служит защитой от атаки патогенной микрофлоры [1-3].

При иммобилизации индивидуального фермента всегда возникает проблема выбора носителя и метода иммобилизации, на котором фермент сохранял бы свою активность продолжительное время. Ранее нами были представлены данные по иммобилизации инулиназы на сверхсшитых сорбентах типа «Стиросорб» [4]. Целью настоящей работы является исследование активности и стабильности полученных биокатализаторов в процессе ферментативного гидролиза инулина.

\section{Экспериментальная часть}

Объектами исследования являлись препараты свободной и иммобилизованной инулиназы

Шкутина Ирина Викторовна - доцент кафедры аналитической химии, кандидат биологических наук, тел.: (473) 2208-932, e-mail: irn55@ mail.ru Стоянова Ольга Федоровна - доцент кафедры аналитической химии, кандидат химических наук, тел.: (473) 2208-932, e-mail: common@ anchem.vsu.ru Селеменев Владимир Федорович - заведующий кафедрой аналитической химии, профессор, доктор химических наук, заслуженный деятель науки РФ, тел.: (473) 2208-932, e-mail: common@anchem.vsu.ru Aspergillus awamori ВКМF 2250, в качестве субстрата использовался инулин («Spofa», Прага). Носителем служил сверхсшитый неионогенный сорбент на основе стирола с дивинилбензолом Стиросорб $\left(\mathrm{S}_{\text {уд. }}=910 \mathrm{~m}^{2} / \Gamma\right)[5]$.

Иммобилизацию осуществляли адсорбционным методом в статических условиях при температуре $20^{\circ} \mathrm{C}$ при периодическом перемешивании

\footnotetext{
* Автор, с которым следует вести переписку.
} 
в течение 4 ч. Общее количество белка в нативных ферментных препаратах определяли методом Лоури, в иммобилизованных ферментах - модифицированным методом Лоури [6]. Десорбция белка в буферные растворы составляла не более $2 \%$. Стандартное отклонение полученных результатов не превышало величину 0,01 .

Определение активности ферментных препаратов проводили в термостатируемом реакторе с перемешиванием. Каталитическую активность измеряли фотометрическим методом по реакции Селиванова с помощью резорцина [7].

Активность инулиназы рассчитывали по формуле

$$
A=\frac{a}{180 b t}
$$

где А - каталитическая активность, ед/мг белка; a - количество образовавшейся фруктозы, мкг; b - концентрация фермента в реакционной смеси, мг/мл гидролизата; $\mathrm{t}$ - время гидролиза, мин; 180 - молекулярная масса фруктозы. При расчете активности иммобилизованного фермента учитывали содержание белка в 1 г носителя.

В работе были исследованы препараты иммобилизованной инулиназы с содержанием белка 25,5 мг/г носителя и активностью 10,8 ед/мг.

Термическую и кислотную инактивацию нативного и иммобилизованного ферментов проводили термостатированием в 0,1 М ацетатном буфере при рН 3,0-6,0, температурах $40-70{ }^{\circ} \mathrm{C}$. Для этого в пробирки помещали соответственно по 10 мл раствора инулиназы и навески 100 мг иммобилизованного препарата, добавляли по 10 мл ацетатного буфера. Растворы инкубировали при данных условиях и через определенные промежутки времени определяли остаточную активность образцов по отношению к $5 \cdot 10^{-4} \mathrm{M}$ раствору инулина.

\section{Обсуждение результатов}

Изучение термо- и рН-стабильности фермента представляет определенный интерес, так как эти показатели могут являться важными характеристиками при разработке методов эффективного использования ферментов на отдельных стадиях технологического процесса. В водных растворах денатурирующие воздействия температуры и рН среды являются взаимосвязанными факторами, и часто их действие рассматривается как совместное. При низких температурах решающую роль в инактивации выполняют ионы водорода, при высоких температурах - тепловая энергия [8]. В производственных условиях ферментативный гидролиз инулина проводят при температуре $50-55{ }^{\circ} \mathrm{C}$ с целью увеличения заданной степени конверсии субстрата и обеспечения бактерицидных условий.

На рисунках 1, 2 показана динамика процесса инактивации свободного и иммобилизованного фермента при температурах $40-70^{\circ} \mathrm{C}$ и $\mathrm{pH} 4,7$, соответствующего максимальной активности инулиназы Aspergillus awamori. При температурах 40-60 ${ }^{\circ} \mathrm{C}$ происходит постепенное снижение каталитической активности препаратов фермента. Дальнейшее увеличение температуры до $70{ }^{\circ} \mathrm{C}$ приводит к более резкому уменьшению активности инулиназы. Так, процент сохранения активности свободной инулиназы после часа инкубации составляет $13 \%$, иммобилизованной - $38 \%$ от первоначальной активности. Это, вероятно, связано с тем, что при сравнительно невысоких температурах происходит разрушение, главным образом, электростатических и водородных связей. При повышении температуры от 60 до $70{ }^{\circ} \mathrm{C}$ скорость инактивации увеличивается, поскольку тепловая энергия вызывает разрушение гидрофобных взаимодействий, которые вносят большой вклад в стабильность белков. В результате этого возникает более глубокое развертывание полипептидной цепи [9].

Количественной характеристикой процесса денатурации белка является константа скорости инактивации [10]. Инактивация ферментов в ряде случаев является реакцией первого порядка и описывается уравнением

$$
k=\frac{2,303}{\tau} \lg \frac{\left[A_{o}\right]}{[A]},
$$

где $\mathrm{k}$ - константа инактивации, мин ${ }^{-1} ;\left[\mathrm{A}_{\mathrm{o}}\right]$ - исходная активность инулиназы, принятая за $100 \%$; [А] - активность фермента в момент времени $\tau$, в \% от исходной; $\tau$ - время, мин. 


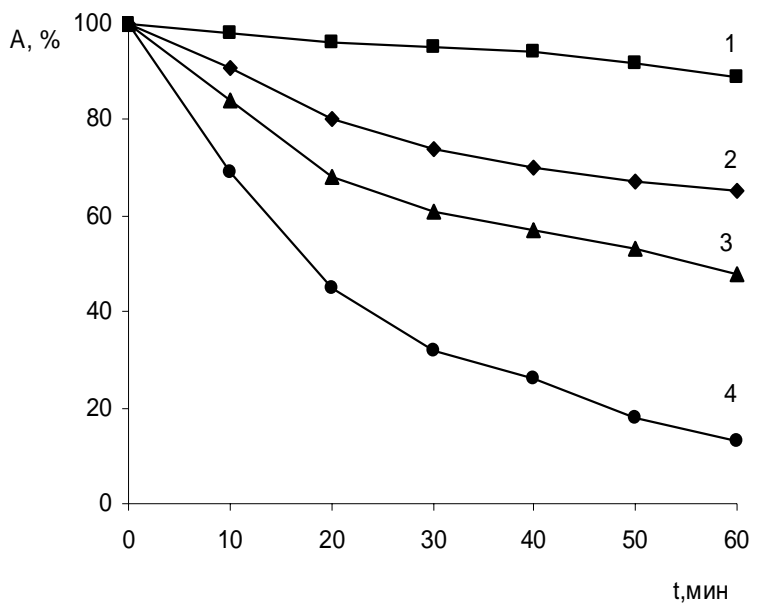

Рис. 1. Кинетические кривые термоинактивации свободной инулиназы: 1 - 40; 2 - 50; 3 - 60; $4-70,{ }^{\circ} \mathrm{C}$. А - активность (\% от максимальной); $\mathrm{t}$ - время инкубации, мин

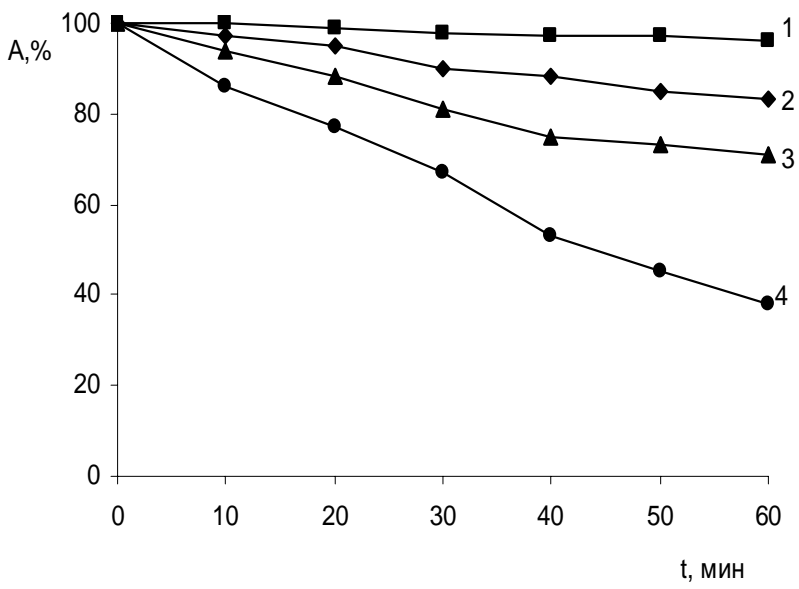

Рис. 2. Кинетические кривые термоинактивации иммобилизованной инулиназы: 1 - 40; 2 - 50; 3 - 60; $4-70,{ }^{\circ} \mathrm{C}$. А - активность (\% от максимальной); $\mathrm{t}-$ время инкубации, мин

Сравнительный анализ совместного действия $\mathrm{pH}$ и температуры на активность свободной и иммобилизованной инулиназы показал, что связывание фермента с носителем приводит к повышению устойчивости белковой макромолекулы. Для иммобилизованного фермента отмечено уменьшение константы инактивации по сравнению с нативным ферментом при всех рассматриваемых условиях (табл.). Данный факт обусловлен тем, что в результате иммобилизации фермент попадает в новую среду, в которой концентрация ионов водорода может отличаться от концентрации ионов в растворе. Поэтому чувствительность иммобилизованной инулиназы к изменению $\mathrm{pH}$ меньше, чем у нативного фермента, и среда носителя обладает фактически буферными свойствами.

Стабилизация иммобилизованного фермента может быть связана с принудительной остановкой поступательного движения молекулы фермента с последующим взаимодействием белка с матрицей носителя. Сорбент Стиросорб обладает высокоразвитой поверхностью, содержащей гидрофобные стиролдивинилбензольные полости. Это позволяет конструировать необходимую архитектуру белковой макромолекулы, обладающей динамическими свойствами, располагать необходимым образом в пространстве структурные единицы. При связывании с носителем происходит повышение жесткости третичной структуры, препятствующей деформационному разворачиванию белковой макромолекулы. Ранее нами также было отмечено повышение термостабильности для другого фермента, относящегося к классу карбогидраз, глюкоамилазы, при иммобилизации на Стиросорбе [11].

При иммобилизации активность ферментов в большинстве случаев снижается, однако интегральная активность, определяемая суммарным количеством полученного продукта, будет выше. В работе было проведено исследование цикличности действия гетерогенного биокатализатора. Для этого носитель с иммобилизованным ферментом (100 мг) помещали в пробирки с субстратом (10 мл 5·10-4 М раствора инулина) и проводили гидролиз, меняя через каждый час субстрат. Выявлено, что гетерогенный биокатализатор можно использовать в среднем в течение 10 циклов. Активность инулиназы, иммобилизованной адсорбционным методом на Стиросорбе, после десяти реакционных циклов составляла $13 \%$ от исходной активности (рис. 3 ).

При хранении фермента при температуре 0-2 ${ }^{\circ} \mathrm{C}$ наблюдалось незначительное снижение каталитической активности по истечении одного года (рис. 4), что свидетельствует об эффективности предложенного способа иммобилизации.

Влияние температуры и рН среды на константу скорости инактивации свободной (I) и иммобилизованной (II) инулиназы

\begin{tabular}{c|c|c|c|c|c|c|c|c}
\hline \multirow{2}{*}{ Температура, ${ }^{\circ} \mathrm{C}$} & \multicolumn{9}{|c|}{$\mathrm{k} \cdot 10^{-3}$, мин $^{-1}$ при $\mathrm{pH}$} \\
\cline { 2 - 9 } & \multicolumn{2}{|c|}{3,2} & \multicolumn{2}{|c|}{4,0} & \multicolumn{2}{c|}{4,7} & \multicolumn{2}{c}{6,2} \\
\cline { 2 - 9 } & I & II & I & II & I & II & I & II \\
\hline 40 & 22,88 & 7,09 & 3,68 & 1,20 & 1,92 & 0,67 & 16,40 & 4,05 \\
50 & 29,24 & 12,82 & 8,70 & 4,74 & 7,11 & 3,08 & 21,04 & 7,63 \\
60 & 46,43 & 21,81 & 15,54 & 6,61 & 12,13 & 5,65 & 26,56 & 12,82 \\
70 & 57,87 & 28,30 & 38,02 & 19,87 & 33,67 & 15,97 & 49,44 & 26,56 \\
\hline
\end{tabular}




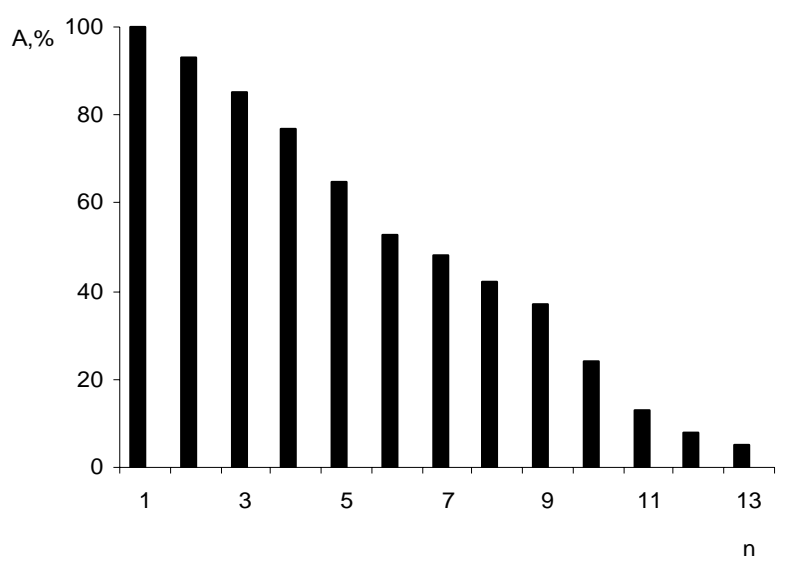

Рис. 3. Кратность использования иммобилизованной инулиназы в реакции гидролиза инулина:

А - активность (\% от максимальной); n - количество реакционных циклов

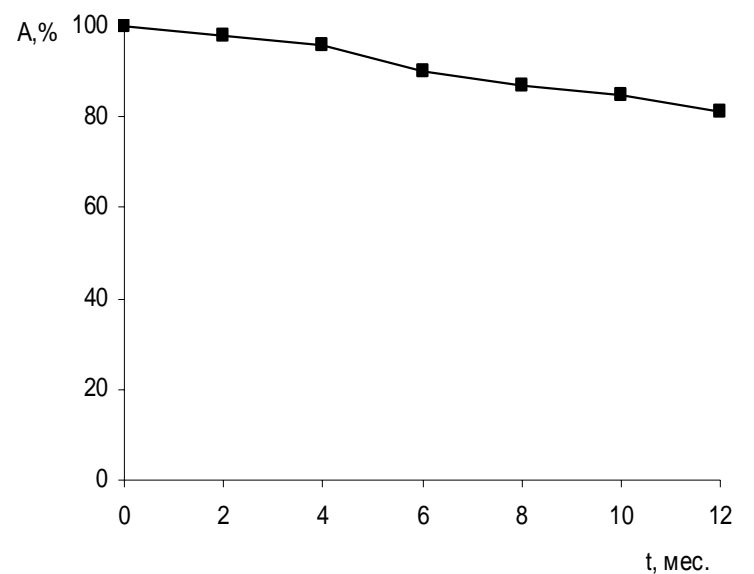

Рис. 4. Изменение активности иммобилизованной инулиназы при хранении: А - активность (\% от максимальной); $\mathrm{t}$ - продолжительность хранения, месяцы

\section{Bыводы}

Изучено влияние температуры и концентрации ионов водорода на активность свободной и иммобилизованной на Стиросорбе инулиназы. Установлено, что гетерогенный биокатализатор отличается большей устойчивостью к денатурирующим факторам среды $(\mathrm{T}, \mathrm{pH})$, чем гомогенный. Подтверждена возможность цикличного применения иммобилизованной инулиназы. Полученные данные могут использоваться для количественной оценки стабильности иммобилизованного фермента в производственных условиях при реакциях биокаталитического превращения инулиносодержащего сырья.

\section{Список литературь}

1. Корнеева О.С. Карбогидразы: препаративное получение, структура и механизм действия на олиго- и полисахариды. Воронеж, 2001. 184 с.

2. Березин И.В. Исследования в области ферментативного катализа и инженерной энзимологии. М., 1990. 382 с.

3. Иммобилизованные клетки и ферменты. Методы : пер. с англ. / под ред. Дж. Вудворда. М., 1988. 215 с.

4. Шкутина И.В., Стоянова О.Ф., Селеменев В.Ф. Гидролиз инулина с помощью гетерогенных биокатализаторов // Химия растительного сырья. 2012. №2. С. 27-31.

5. Davankov V.A., Tsyurupa M.P. Hypercrosslinked polymers basic principle of preparing the new class of polymeric materials // Reactive Polymers. 2002. Vol. 53, N.1. Pp. 193-203.

6. Chibata I. Industrial application of immobilized enzyme system // Pure and Appl. Chem. 1978. Vol. 50, N7. Pp. 667-675.

7. Nakamura T., Nakatsu S. General properties of extracellar inulase from Penicillum // J. Agr. Chem. Loc. Jap. 1997. Vol. 1, N 12. Pp. 681-689.

8. Жоли М. Физическая химия денатурации белков. М., 1968. 364 с.

9. Путнам Ф. Денатурация белков. М., 1984. 294 с.

10. Варфоломеев С.Д., Гуревич К.Г. Биокинетика : практический курс. М., 1999. 720 с.

11. Шкутина И.В., Стоянова О.Ф., Селеменев В.Ф., Григорьева Г.А. Зависимость термостабильности свободной и иммобилизованной глюкоамилазы от концентрации ионов водорода // Журнал физической химии. 2001. Т. 75, №12. С. 2292-2293. 
Shkutina I.V., Stoyanova O.F., Selemenev V.F. BIOCATALYTIC PROPERTIES OF IMMOBILIZED INULINASE

Voronezh State University, Department of Chemistry, Universitetskaya pl.,1, Voronezh, 394006 (Russia), e-mail: irn55@mail.ru

The heterogeneous biocatalyst based on inulinase immobilized on the non-ionogenic sorbent of Stirosorb was proposed. Investigation of thermic and acid inactivation of free and immobilized inulinase was carried out. The corresponding values of the inactivation constants were rated. Increase of thermal stability of the immobilized ferment compared to the free one was exposed. Possibility of use of the immobilized ferment ten cycles long during the reaction of inulin hydrolysis was determined.

Keywords: inulinase, Stirosorb, immobilization, catalytic activity, acid, thermic inactivation, inactivation constant.

\section{References}

1. Korneeva O.S. Karbogidrazy: preparativnoe poluchenie, struktura i mekhanizm deistviia na oligo- $i$ polisakharidy. [Carbohydrases: Preparative preparation, structure and mechanism of action on oligo- and polysaccharides]. Voronezh, 2001, 184 p. (in Russ.).

2. Berezin I.V. Issledovaniia v oblasti fermentativnogo kataliza i inzhenernoi enzimologii. [Studies in the region of fermentative catalysis and engineering enzymology]. Moscow, 1990, 382 p. (in Russ.).

3. Immobilizovannye kletki i fermenty. [Immobilized cells and enzymes.]. Ed. J. Woodward. Moscow, 1988, 215 p. (in Russ.).

4. Shkutina I.V., Stoianova O.F., Selemenev V.F. Khimiia rastitel'nogo syr'ia, 2012, no. 2, pp. 27-31. (in Russ.).

5. Davankov V.A., Tsyurupa M.P. Reactive Polymers, 2002, vol. 53, no. 1, pp. 193-203.

6. Chibata I. Pure and Appl. Chem., 1978, vol. 50, no. 7, pp. 667-675.

7. Nakamura T., Nakatsu S. J. Agr. Chem. Loc. Jap., 1997, vol. 1, no. 12, pp. 681- 689.

8. Zholi M. Fizicheskaia khimiia denaturatsii belkov. [Physical chemistry of protein denaturation]. Moscow, 1968, 364 p. (in Russ.).

9. Putnam F. Denaturatsiia belkov. [Protein denaturation]. Moscow, 1984, 294 p. (in Russ.).

10. Varfolomeev S.D., Gurevich K.G. Biokinetika : Prakticheskii kurs. [Biokinetics: Practical Course]. Moscow, 1999, 720 p. (in Russ.).

11. Shkutina I.V., Stoianova O.F., Selemenev V.F., Grigor'eva G.A. Zhurnal fizicheskoi khimii, 2001, vol. 75, no. 12, pp. 2292-2293. (in Russ.).

Received November 5, 2012

\footnotetext{
* Corresponding author.
} 
